\title{
Whole and fractionated yellow pea flours reduce fasting insulin and insulin resistance in hypercholesterolaemic and overweight human subjects
}

\author{
Christopher P. F. Marinangeli and Peter J. H. Jones* \\ The Richardson Centre for Functional Foods and Nutraceuticals, University of Manitoba, 196 Innovation Drive, Winnipeg, \\ $M B$, Canada R3T 2N2 \\ (Received 10 February 2010 - Revised 16 July 2010 - Accepted 17 July 2010 - First published online 1 September 2010)
}

\section{Abstract}

The objective of the present study was to compare whole pea flour (WPF) to fractionated pea flour (FPF; hulls only) for their ability to reduce risk factors associated with CVD and diabetes in overweight hypercholesterolaemic individuals. Using a cross-over design, twenty-three hypercholesterolaemic overweight men and women received two-treatment muffins/d containing WPF, FPF or white wheat flour (WF) for $28 \mathrm{~d}$, followed by $28 \mathrm{~d}$ washout periods. Daily doses of WPF and FPF complied with the United States Department of Agriculture's recommended level of intake of half a cup of pulses/d (approximately $50 \mathrm{~g} / \mathrm{d}$ ). Dietary energy requirements were calculated for each study subject, and volunteers were only permitted to eat food supplied by the study personnel. Fasting insulin, body composition, urinary enterolactone levels, postprandial glucose response, as well as fasting lipid and glucose concentrations, were assessed at the beginning and at the end of each treatment. Insulin concentrations for WPF $(37 \cdot 8(\mathrm{sEM} 3 \cdot 4) \mathrm{pmol} / \mathrm{ml}, P=0 \cdot 021)$ and FPF (40.5 (SEM 3.4) pmol $/ \mathrm{ml}, P=0.037)$ were lower compared with WF (50.7 (sEM 3.4$) \mathrm{pmol} / \mathrm{ml}$ ). Insulin homeostasis modelling assessment showed that consumption of WPF and FPF decreased $(P<0.05)$ estimates of insulin resistance (IR) compared with WF. Android: gynoid fat ratios in women participants were lower $(P=0.027)$ in the WPF (1.01 (SEM 0.01) group compared with the WF group (1.06 (SEM $0 \cdot 01)$. Urinary enterolactone levels tended to be higher $(P=0.087)$ in WPF compared with WF. Neither treatment altered circulating fasting lipids or glucose concentrations. In conclusion, under a controlled diet paradigm, a daily consumption of whole and fractionated yellow pea flours at doses equivalent to half a cup of yellow peas/d reduced IR, while WPF reduced android adiposity in women.

\section{Key words: Peas: Insulin: Insulin sensitivity: Adipose tissue distribution}

Pulses are annual leguminous crops that include lentils, beans, chickpeas and yellow peas. Pulse crops are high in protein, antioxidants and fibre, and low in fat and energy, all these factors contribute to the reduction of CVD and type 2 diabetes mellitus risk ${ }^{(1,2)}$. The United States Department of Agriculture (USDA) recommends that adults consume half a cup of legumes/d, including pulses, as part of a healthy diet. Typically, pulse consumption is recommended to diabetics as a means of controlling postprandial glycaemia. However, animal and human studies have noted that the consumption of chickpeas, beans and lentils also reduces circulating lipid and glucose concentrations, while improving body composition by decreasing percentage fat mass ${ }^{(3-5)}$. Although satiety and reduced food intake are believed to contribute to health benefits associated with pulse crops ${ }^{(6)}$, the effects of individual pulse crops remain poorly characterised.
Health benefits of yellow peas have been given little attention in human clinical trials, despite being a low-cost commodity with widespread consumption worldwide. Yellow peas consist of an outer layer known as the seed coat or hull and an inner portion termed as the cotyledon. The seed coat contains 85-90\% fibre, while the cotyledon is higher in protein and unsaturated fat. In addition, yellow peas are a source of secoisolariciresinol ${ }^{(7)}$, a phyto-oestrogen that is metabolised by colonic microflora to enterolactone ${ }^{(8)}$. Investigating how sub-components of yellow peas have an impact on indices of health is likely to shed light on which portion of yellow peas possesses the most health benefits, bringing awareness about yellow peas as a dietary approach for CVD and diabetes prevention.

Evaluating and classifying how various fractions of pulse crops have an impact on health will serve as a rationale for isolating and concentrating their components for inclusion into diets that do not utilise pulse crops as staple foods.

Abbreviations: ER, oestrogen receptor; FPF, fractionated yellow pea flour; HDL-C, HDL-cholesterol; HOMA, homeostasis modelling assessment; IR, insulin resistance; LDL-C, LDL-cholesterol; TC, total cholesterol; TFM, total fat mass; USDA, United States Department of Agriculture; WF, white wheat flour; WPF, whole pea flour. 
The production of novel pulse-derived flours serves as a new platform for administering pulse fractions, enabling new and flexible approaches for incorporating pulsederived components into North American diets. As such, the objective of the present study was to evaluate the efficacy of whole and fractionated yellow pea flours in reducing risk factors associated with CVD and diabetes while controlling food and energy intake.

\section{Methods}

\section{Subjects}

Twenty-nine hypercholesterolaemic, overweight (BMI $25-40 \mathrm{~kg} / \mathrm{m}^{2}$ ) men and women were recruited from the Winnipeg area using newspaper and radio advertisements. Baseline characteristics of the participants are summarised in Table 1. Exclusion criteria included smoking, the use of prescription and natural lipid-lowering therapies, history of myocardial infarction, coronary artery bypass, angina, congestive heart failure, inflammatory bowel disease, pancreatitis, renal disease, diabetes and a history of chronic alcohol usage $(>2$ drinks/d). Individuals with cancer, eating disorders and those who reported expending $>16747 \mathrm{~kJ} /$ week through exercise were also excluded from the participation. The participants taking medications for other ailments were included providing their daily dose of medication remained stable for the duration of the study. The present study was conducted according to the guidelines laid down in the Declaration of Helsinki, and all procedures involving human subjects/ patients were approved by the University of Manitoba's Biomedical Research Ethics Board (B2006: 129). A written informed consent was obtained from all the participants. The present study was registered at www.clincialtrials.gov, ID NCT00839774 (6 February 2009).

\section{Treatments}

Treatments consisted of whole pea flour (WPF), fractionated pea flour (FPF; hulls only) and white wheat flour (WF; control). Treatment flours were administered with

Table 1. Baseline characteristics of study subjects

(Mean values and standard deviations)

\begin{tabular}{lccccc}
\hline & \multicolumn{2}{c}{ Men $(n 10)$} & & \multicolumn{2}{c}{ Women $(n 19)$} \\
\cline { 2 - 3 } Criteria & Mean & SD & & Mean & SD \\
\hline Age (years) & 51.8 & 12.3 & & 52.3 & 10.0 \\
Wt $(\mathrm{kg})$ & 95.0 & 18.6 & & 80.4 & 12.1 \\
BMl $\left(\mathrm{kg} / \mathrm{m}^{2}\right)$ & 31.7 & 5.3 & & 29.4 & 3.5 \\
TC $(\mathrm{mmol} / \mathrm{l})$ & 5.63 & 0.53 & & 6.26 & 0.81 \\
LDL-C $(\mathrm{mmol} / \mathrm{l})$ & 3.32 & 0.96 & & 3.92 & 0.75 \\
HDL-C $(\mathrm{mmol} / \mathrm{l})$ & 1.11 & 0.14 & & 1.52 & 0.33 \\
TAG $(\mathrm{mmol} / \mathrm{l})$ & 2.52 & 1.31 & & 1.85 & 1.04 \\
Glucose $(\mathrm{mmol} / \mathrm{l})$ & 5.79 & 1.32 & & 4.84 & 0.49 \\
\hline
\end{tabular}

TC, total cholesterol; LDL-C, LDL-cholesterol; HDL-C, HDL-cholesterol. banana and apple muffins to subjects. Muffin recipes were developed at the Richardson Centre for Functional Foods and Nutraceuticals clinical kitchen. WPF and FPF flours were obtained from Best Cooking Pulses, Inc. (Portage la Prairie, MB, Canada), while the WF was obtained from a local supermarket. Pea treatment flours were analysed by Medallion Labs (Minneapolis, MN, USA) to determine their nutrient composition (Table 2). The composition of WF was determined by available food analysis tables ${ }^{(9)}$. The current USDA recommendations for pulse consumption are half a cup/d, which is approximately $50 \mathrm{~g}$ dry whole yellow peas ${ }^{(10)}$. Each WPF treatment muffin was formulated to contain approximately $25 \mathrm{~g}, 50 \%$ the USDA recommended daily serving of pulses. Given that two WPF treatments were equivalent to $1 / 2$ cups/d dry yellow peas $(50 \mathrm{~g})$, the subjects were required to eat two treatment muffins/d. The FPF treatment muffins were formulated based on the total pea-derived fibre content of the WPF muffin since the pea hull flour used in the present study was approximately $84.2 \%$ fibre (Table 2). Hence, the amount of fractionated flour added to the FPF muffin recipe was adjusted to equal the amount of fibre in the WPF treatment (Table 3). The balance of the muffin weight was white wheat flour. Adjusting FPF treatments to contain the same amount of pea fibre as the WPF treatment enabled distinguishing of whether it was the fibre component of the USDA's recommended intake of pulses that conferred health benefits or the cotyledon

Table 2. Composition of treatment flours and treatment muffins

\begin{tabular}{|c|c|c|c|}
\hline & WPF* $^{*}$ & FPF* $^{\star}$ & WF† \\
\hline \multicolumn{4}{|l|}{ Treatment flour } \\
\hline Energy $(\mathrm{kJ} / 100 \mathrm{~g})$ & 1281 & 343 & 1482 \\
\hline Total carbohydrate (\%) & $66 \cdot 3$ & $89 \cdot 0$ & $79 \cdot 4$ \\
\hline Available carbohydrate (\%) & $50 \cdot 7$ & $12 \cdot 7$ & $76 \cdot 3$ \\
\hline Fibre (\%) & $17 \cdot 6$ & $84 \cdot 2$ & $3 \cdot 1$ \\
\hline Soluble & $2 \cdot 0$ & 7.9 & 1.8 \\
\hline Insoluble & $15 \cdot 6$ & $76 \cdot 3$ & $1 \cdot 3$ \\
\hline Total fat & $1 \cdot 84$ & 0.63 & $1 \cdot 0$ \\
\hline Polyunsaturated fat (\%) & 0.98 & 0.31 & 0.41 \\
\hline Monounsaturated fat (\%) & 0.44 & 0.13 & 0.09 \\
\hline Saturated (\%) & 0.34 & 0.16 & 0.15 \\
\hline Protein (\%) & $21 \cdot 6$ & $6 \cdot 39$ & $10 \cdot 3$ \\
\hline \multicolumn{4}{|l|}{ Treatment muffins } \\
\hline Whole pea flour per muffin (g) & $26 \cdot 4$ & - & - \\
\hline Fractionated pea flour per muffin (g) & - & $6 \cdot 0$ & - \\
\hline White wheat flour per muffin $(\mathrm{g})$ & - & $20 \cdot 4$ & $26 \cdot 4$ \\
\hline Wt per muffin $(g)$ & 91 & 91 & 91 \\
\hline Energy (kJ) & 821.5 & $816 \cdot 9$ & 888.5 \\
\hline Carbohydrate (g) & 30.4 & 33.8 & $33 \cdot 0$ \\
\hline Total fibre $(\mathrm{g})$ & $5 \cdot 8$ & $6 \cdot 9$ & $2 \cdot 0$ \\
\hline Soluble fibre & $1 \cdot 7$ & $2 \cdot 0$ & $1 \cdot 6$ \\
\hline Insoluble fibre & $4 \cdot 1$ & $4 \cdot 8$ & 0.3 \\
\hline Total fat $(g)$ & $7 \cdot 4$ & $7 \cdot 1$ & $7 \cdot 1$ \\
\hline Polyunsaturated fat & $3 \cdot 8$ & $3 \cdot 7$ & $3 \cdot 7$ \\
\hline Monounsaturated fat & $3 \cdot 2$ & $3 \cdot 1$ & $3 \cdot 1$ \\
\hline Saturated fat & 0.9 & 0.8 & 0.8 \\
\hline Protein (g) & $7 \cdot 1$ & 3.9 & $4 \cdot 1$ \\
\hline
\end{tabular}

WPF, whole pea flour; FPF, fractionated pea flour; WF, white wheat flour. * Treatment flours analysed at Medallion Labs (Minneapolis, MN, USA). †Flour composition determined using available nutritional tables ${ }^{(9)}$. 
Table 3. Energy requirements and background diet composition for study participants

\begin{tabular}{lc}
\hline Diet composition (\%) & \\
Carbohydrate & 55 \\
Protein & 15 \\
Fat & 30 \\
Diet summary* & \\
Energy $(\mathrm{MJ}) / \mathrm{d}$ & 12.56 \\
Carbohydrate (g) & 403.7 \\
Protein (g) & 113.2 \\
Fat (g) & 97.3 \\
Polyunsaturated fat $\dagger$ & $19.6(6 \%)$ \\
Monounsaturated fat† & $20.8(6 \%)$ \\
Saturated fat† & $25.1(8 \%)$ \\
Dietary fibre (g) & $18 \cdot 8$ \\
Soluble fibre & 4.8 \\
Cholesterol (mg) & 238.8 \\
\hline
\end{tabular}

* Nutritional summary is based on a $12.56 \mathrm{MJ} / \mathrm{d}$ diet.

† Values in parentheses denote percentage of total energy.

component of WPF. The WF muffin was solely comprised of white wheat flour. Xanthin gum was added to all the muffin recipes at $2.0 \%$ of total flour weight to compensate for WPF and FPF flours lacking gluten.

\section{Study design}

The present study used a single-blind, cross-over design. The study consisted of three 4-week study phases, each followed by a 4-week washout. To determine the treatment order within each subject, the participants were randomly assigned to one of the six possible treatment sequences.

Diet and treatment protocol. For the duration of each study phase, the subjects only consumed food provided by the Richardson Centre for Functional Foods and Nutraceuticals clinical research kitchen. The nutrient composition of the study diet was analysed using Food Processor version 7.71 (ESHA Research, Portland, OR, USA) as is summarised in Table 3. The background diet was in accordance with the American Heart Association's National Cholesterol Education Program (NCEP)-Step 1 diet. Diets did not contain any pulse products apart from the treatment muffins. To prevent body weight change for the duration of each study phase, daily energy requirements for each subject were determined by calculating individual RMR using the Mifflin equation $^{(11)}$, then by applying an activity factor of 1.7 . The amount of food the each participant received was based on individual calculated energy requirements. The average energetic content of two treatment muffins (approximately $1675 \mathrm{~kJ}$ ) was subtracted from the total calculated energy requirements to compensate for the energy intake from WPF, FPF and WF. Body weights were assessed daily. If a subject's weight increased or decreased in the first week of each study phase, the energy intake was adjusted accordingly. Each morning, the study participants were required to visit the Richardson Centre for Functional Foods and Nutraceuticals clinical research unit to consume breakfast and one bananaflavoured treatment muffin under supervision. The participants would then leave the unit with a cooler containing the remainder of their meals and snacks along with an apple-flavoured treatment muffin to consume with dinner. Returned empty, unwashed food containers were used to monitor compliance.

Blood collection protocol. Twelve-hour fasting serum and plasma blood samples were collected on days 1, 2, 28 and 29 of each study phase. Blood was centrifuged at $3000 \mathrm{rpm}$ at $4^{\circ} \mathrm{C}$ to separate serum and plasma from erythrocytes, which were then stored at $-80^{\circ} \mathrm{C}$ until analysed.

Fasting insulin values and insulin homeostasis modelling assessment. Fasting plasma insulin concentrations were determined using ELISA (Millipore, Linco Research, St Charles, MO, USA). The average CV\% between duplicate samples was $1.0 \%$. The resultant insulin values were transformed from $\mu \mathrm{U} / \mathrm{ml}$ to $\mathrm{pmol} / \mathrm{ml}$ by multiplying values by a factor of $6 \cdot 0^{(12)}$. Insulin homeostasis modelling assessment (HOMA) was utilised as an estimate for $\% \beta$-cell function and insulin resistance (IR). The HOMA values were calculated using methods outlined by Matthews et al. ${ }^{(13)}$. Baseline and endpoint insulin parameters were reported as the average between day 1 and 2 and day 28 and 29 values, respectively.

Glucose response protocol. Glucose responses to the breakfast meal and treatment were determined during the first and last weeks of each study phase. Fasting glucose concentrations were determined using a finger-prick blood glucose monitor (Accu-chek plus; Roche Diagnostics, Laval, QC, Canada). The subjects had $40 \mathrm{~min}$ to eat their energetically calculated breakfast and one treatment muffin (approximately a quarter cup of peas). Glucose concentrations were assessed before and at 40, 70, 130 and $190 \mathrm{~min}$ following the initiation of breakfast. For logistic reasons, we were unable to assess blood glucose across 15 min intervals, the period typically used when assessing glucose response ${ }^{(14)}$. In addition to assessing postprandial glucose response, the subjects were simultaneously undergoing postprandial energetic responses via indirect calorimetry at 30 and $60 \mathrm{~min}$ increments. Hence, blood glucose measurements were assessed after the subjects completed an energetic measurement interval. If blood glucose measurements were taken during indirect calorimetry intervals, the finger-prick utilised to take blood samples would have induced stress and skewed $\mathrm{O}_{2}$ consumption and $\mathrm{CO}_{2}$ production and jeopardised the integrity of data collected during the assessment of energy expenditure. At least two blood glucose readings were taken at each time point. A third measurement was taken if glucose values were $>0.3 \mathrm{mmol} / 1$ apart. Finally, two quality assurance solutions containing known amounts of either high glucose or low glucose levels were used daily to ensure glucose monitors produced accurate results.

Incremental areas under the curve for glucose response curves were determined using the methodologies outlined 
by Wolever \& Jenkins ${ }^{(15)}$. Briefly, the area below baseline was subtracted from the total incremental areas under the curve values. If the data points fell below baseline, only areas above the baseline value were considered.

Body composition protocol. Body composition, including percentage of total fat mass (\%TFM), TFM and total lean mass, as well as percentage android and gynoid fat, were assessed on days 1 and 29 of each study phase using fan beam dual-energy X-ray absorptiometry (Lunar Prodigy Advance; GE Healthcare, Madison, WI, USA). Body composition data including \%TFM, TFM, total lean mass, android fat and gynoid fat deposition were determined using Encore 2005 software version 9.30.044 (GE Healthcare). Encore 2005 also calculated android:gynoid fat ratios by dividing $\%$ android fat by $\%$ gynoid fat.

Urinary enterolactone levels. Morning-fasted urine samples were collected on day 29 of each study phase. The subjects were instructed not to void their bladder at home before arriving at the Richardson Centre for Functional Foods and Nutraceuticals. The urine samples were aliquoted and stored at $-80^{\circ} \mathrm{C}$ until analysis. Urinary enterlactone levels were analysed by competitive enzyme immunoassay (Cayman Chemical, Ann Arbor, MI, USA). All the samples were diluted $1000 \times$ before enzyme immunoassay analysis. Urinary creatinine levels were determined enzymatically (Vitros 350; Ortho-clinical Diagnostics, Inc., Rochester, NY, USA) and used to normalise urinary enterolactone values.

Fasting lipid and glucose profile. Day 1, 2, 28 and 29 serum total cholesterol (TC), HDL-cholesterol (HDL-C), TAG and glucose concentrations were analysed enzymatically (Vitros 350; Ortho-clinical Diagnostics, Inc.). LDLcholesterol (LDL-C) concentrations were calculated using the Friedewald equation ${ }^{(16)}$. Baseline and endpoint lipid and glucose parameters were reported as the average between days 1 and 2 and days 28 and 29 values, respectively.

\section{Statistics}

The results are presented as means with their standard errors. Differences in endpoint values between treatment groups for body composition, TC, LDL-C, TAG, HDL-C, glucose, insulin and HOMA data were analysed using linear mixed-model ANOVA with subject as a random factor. Normality was assessed using the Shapiro-Wilk test, as well as evaluating linearity and clustering in normal and disturbed $Q-Q$ plots, respectively. Circulatory TAG, HDL-C concentrations, HOMA variables and urinary entrolactone levels did not follow a normal distribution, and they were log-transformed for statistical analysis. For reporting purposes, means with their standard errors were back-transformed to physiological values. For glucose response, total effect of treatment over time was assessed using repeated measures. For all ANOVA, estimated means were compared using the Bonferroni post boc test when significant differences were noted. Intra-treatment differences between start-phase and end-phase values were determined using paired $t$ tests. A level of significance at $P<0.05$ was used in all the analyses. The data were analysed using SPSS software version 11.5 (SPSS, Inc., Chicago, IL, USA).

\section{Results}

\section{Subject dropout and compliance}

Of the twenty-nine individuals who participated in the study, twenty-three subjects completed the entire 12week trial. Two subjects discontinued the study for medical reasons, while four subjects dropped out for personal reasons. After dropouts, the number of men and women in the study were seven and sixteen, respectively. One subject was taking aspirin over the course of the study. No other subject was consuming over-the-counter or prescription medications over the course of the study. Statistical analysis for all measurements revealed no effect of sex, age or an age $\times$ sex interaction.

Table 4. Effects of treatment on fasting insulin, markers of insulin resistance (IR), postprandial glycaemic response, fat distribution and urinary enterolactone levels

(Mean values with their standard errors, $n$ 23)

\begin{tabular}{|c|c|c|c|c|c|c|c|}
\hline & \multicolumn{2}{|c|}{ WF } & \multicolumn{2}{|c|}{ WPF } & \multicolumn{2}{|c|}{ FPF } & \multirow[b]{2}{*}{$P \dagger$} \\
\hline & Mean & SEM & Mean & SEM & Mean & SEM & \\
\hline Fasting insulin (pmol/ml) & $50 \cdot 7^{a}$ & 3.4 & $37 \cdot 8^{\mathrm{b} *}$ & 3.4 & $40 \cdot 5^{\mathrm{b} *}$ & 3.4 & 0.013 \\
\hline HOMA-IR (ratio) & $1.9^{\mathrm{a}}$ & 0.2 & $1.5^{\mathrm{b} *}$ & $0 \cdot 2$ & $1.5^{\mathrm{b} *}$ & 0.2 & 0.08 \\
\hline HOMA- $\beta$-cell (\%) & $105 \cdot 4$ & 8.4 & 83.4 & 8.4 & $91 \cdot 8$ & 8.4 & 0.157 \\
\hline Glycaemic response $(\mathrm{IAUC}, \mathrm{mmol} \times \mathrm{min} / \mathrm{l})$ & 414.7 & $26 \cdot 6$ & $379 \cdot 1$ & $27 \cdot 3$ & 397.5 & $29 \cdot 1$ & 0.578 \\
\hline Android:gynoid ratio & $1.14^{\mathrm{a}}$ & 0.01 & $1 \cdot 10^{\mathrm{b} * *}$ & 0.01 & $1 \cdot 11^{\mathrm{a}}$ & 0.01 & 0.049 \\
\hline Females & $1.06^{\mathrm{a}}$ & 0.01 & $1.01^{\mathrm{b} *}$ & 0.01 & $1.04^{\mathrm{a}}$ & 0.01 & 0.031 \\
\hline Males & $1 \cdot 31$ & 0.06 & 1.30 & 0.06 & $1 \cdot 30$ & 0.06 & 0.626 \\
\hline Urinary enterolactone ( $\mathrm{nmol} / \mathrm{mmol}$ creatinine) & $10 \cdot 4^{\mathrm{a}}$ & $2 \cdot 7$ & $12 \cdot 0^{\mathrm{b} * \star}$ & $2 \cdot 7$ & $11.8^{\mathrm{a}}$ & 2.7 & 0.045 \\
\hline
\end{tabular}

WF, white wheat flour; WPF, whole pea flour; FPF, fractioned pea flour; HOMA, insulin homeostasis modelling assessment; IAUC, incremental area under the curve.

a,b Mean values within a row with unlike superscript letters were significantly different: ${ }^{\star} P<0 \cdot 05,{ }^{\star \star} P<0 \cdot 1$.

†Treatment effect for ANOVA or ANCOVA across treatments. 
Fasting insulin and insulin homeostasis modelling assessment for insulin resistance and $\% \beta$-cell function

End-phase fasting insulin concentrations were reduced during WPF $(P=0.021)$ and FPF $(P=0.037)$ treatments, respectively, compared with WF (Table 4). No differences were observed for endpoint insulin concentrations between WPF and FPF treatments. Furthermore, withinphase analysis revealed that WPF and FPF significantly reduced fasting insulin by 13.5 (SEM 4.8$) \%(P=0.009)$ and $9 \cdot 8$ (SЕм 4.8$) \%(P=0.045)$ from baseline compared with WF (Table 4). No differences in percentage change between baseline and endpoint were observed between WPF and FPF.

HOMA for insulin revealed that estimates of IR were reduced to $25 \%$ in the WPF and FPF groups, respectively, compared with the WF group (Table 4). However, estimates of $\% \beta$-cell function were not different between the groups. Percentage differences from baseline did not significantly differ between WPF, FPF and WF treatments for HOMA-based markers of $\% \beta$-cell function and IR, respectively.

\section{Body composition}

Intra-phase body weights between days 1 and 29 were stable at 84.9 (SEM 0.6), 85.7 (SEM 0.6) and 84.3 (SEM $0 \cdot 6) \mathrm{kg}$ for WPF, FPF and WF, respectively. Dual-energy $\mathrm{X}$-ray absorptiometry analysis revealed that WPF, FPF and WF had no effect on endpoint values or calculated intra-treatment percentage differences for \%TFM, android fat or gynoid fat. While no changes were noted between WF and WPF compared to FPF, there was a trend towards a reduction $(P=0.059)$ in the android:gynoid ratio for WPF $v$. WF. However, when stratified by sex, females ( $n$ 16) administered with WPF demonstrated a $4.7 \%$ reduction $(P=0.027)$ in android:gynoid ratios compared with when they received WF (Table 4).

\section{Postprandial g/ucose response}

No treatment differences were observed in postprandial glucose incremental areas under the curve for endpoint and percentage change from baseline.

\section{Urinary enterolactone levels}

Urinary enterolactone levels tended to be higher $(P=0 \cdot 084)$ in the WPF group compared with those in the WF group (Table 4).

\section{Fasting serum lipid and glucose concentrations}

Within-group reductions in TC and LDL-C were observed in all three treatment groups, along with decreases in HDL-C in the WPF and WF groups compared with baseline (Table 5). Fasting glucose decreased in the FPF group compared with baseline. However, no effect on fasting serum TC, LDL-C, HDL-C, TAG or glucose concentrations were observed between the treatment groups (Table 5).

Table 5. Summary of fasting lipid and glucose values

(Mean values with their standard errors, $n$ 23)

\begin{tabular}{|c|c|c|c|c|c|c|c|}
\hline \multirow[b]{2}{*}{ Endpoint } & \multicolumn{2}{|c|}{ WPF } & \multicolumn{2}{|c|}{ FPF } & \multicolumn{2}{|c|}{ WF } & \multirow[b]{2}{*}{$P \dagger$} \\
\hline & Mean & SEM & Mean & SEM & Mean & SEM & \\
\hline \multicolumn{8}{|l|}{ TC } \\
\hline Start phase $(\mathrm{mmol} / \mathrm{l})$ & $6 \cdot 16$ & 0.16 & $6 \cdot 12$ & $0 \cdot 15$ & $6 \cdot 14$ & 0.17 & \\
\hline End phase $(\mathrm{mmol} / \mathrm{l})$ & $5 \cdot 50^{\star \star \star}$ & 0.13 & $5 \cdot 51^{\star \star}$ & 0.13 & $5 \cdot 42^{\star \star \star}$ & 0.13 & 0.678 \\
\hline Change $(\%) \ddagger$ & $-9 \cdot 7$ & $2 \cdot 1$ & $-9 \cdot 0$ & $2 \cdot 1$ & $-10 \cdot 6$ & $2 \cdot 1$ & 0.813 \\
\hline \multicolumn{8}{|l|}{ LDL-C } \\
\hline Start phase $(\mathrm{mmol} / \mathrm{l})$ & 3.78 & 0.13 & $3 \cdot 70$ & $0 \cdot 12$ & 3.81 & 0.13 & \\
\hline End phase $(\mathrm{mmol} / \mathrm{l})$ & $3 \cdot 21^{\star \star}$ & 0.13 & $3 \cdot 14^{\star *}$ & $0 \cdot 13$ & $3 \cdot 11^{\star \star *}$ & 0.13 & 0.398 \\
\hline Change $(\%) \ddagger$ & $-13 \cdot 2$ & 3.0 & $-13 \cdot 3$ & $3 \cdot 0$ & $-16 \cdot 1$ & 3.0 & 1.000 \\
\hline \multicolumn{8}{|l|}{ HDL-C } \\
\hline Start phase $(\mathrm{mmol} / \mathrm{l})$ & 1.36 & 0.08 & 1.32 & 0.07 & $1 \cdot 37$ & 0.07 & \\
\hline End phase $(\mathrm{mmol} / \mathrm{l})$ & $1 \cdot 16^{\star}$ & 0.05 & $1 \cdot 20$ & 0.05 & $1 \cdot 14^{\star \star \star}$ & 0.05 & 0.370 \\
\hline Change (\%)‡ & -8.4 & 2.5 & $-5 \cdot 8$ & $2 \cdot 5$ & $-10 \cdot 7$ & $2 \cdot 5$ & 0.218 \\
\hline \multicolumn{8}{|l|}{ TAG } \\
\hline Start phase $(\mathrm{mmol} / \mathrm{l})$ & $2 \cdot 24$ & 0.22 & $2 \cdot 31$ & 0.25 & $2 \cdot 12$ & 0.21 & \\
\hline End phase $(\mathrm{mmol} / \mathrm{l})$ & $2 \cdot 34$ & $0 \cdot 17$ & $2 \cdot 33$ & $0 \cdot 17$ & $2 \cdot 41$ & 0.17 & 0.674 \\
\hline Change (\%)‡ & 4.5 & $7 \cdot 3$ & 0.8 & $7 \cdot 3$ & $8 \cdot 1$ & 7.5 & 0.651 \\
\hline \multicolumn{8}{|l|}{ Glucose } \\
\hline Start phase $(\mathrm{mmol} / \mathrm{l})$ & $5 \cdot 30$ & 0.14 & $5 \cdot 32$ & $0 \cdot 14$ & $5 \cdot 28$ & 0.18 & \\
\hline End phase $(\mathrm{mmol} / \mathrm{l})$ & $5 \cdot 00$ & 0.08 & $5 \cdot 00^{*}$ & 0.08 & $5 \cdot 03$ & 0.08 & 0.855 \\
\hline Change (\%)‡ & $-1 \cdot 2$ & 1.4 & -3.2 & 1.4 & -0.2 & 1.4 & 0.161 \\
\hline
\end{tabular}

WPF, whole pea flour; FPF, fractioned pea flour; WF, white wheat flour, TC, total cholesterol; LDL-C, LDL-cholesterol; HDL-C, HDL cholesterol.

Mean values were significantly different from those of the days 1 and $2:{ }^{\star} P<0.05,{ }^{* \star} P<0.002,{ }^{\star \star \star} P<0.001$.

$\dagger$ Treatment effect for ANOVA across treatments. Statistical significance was set at $P<0.05$.

$\ddagger$ Percentage change is based on individual data. 


\section{Discussion}

The novel findings presented demonstrate that under conditions that control for food and energy intake, the USDA's recommended dose of $50 \mathrm{~g} / \mathrm{d}$ WPF (half a cup) and FPF, normalised to the fibre content in the WPF treatment, effectively reduced fasting insulin concentrations, and IR in hypercholesterolaemic, overweight individuals. In addition, women consuming WPF showed lower android:gynoid fat ratios compared with WF.

The observation that both the pea treatments produced the same effect on fasting insulin concentrations suggests that pea fibre was the efficacious bioactive substance responsible for that action. It is likely that the effect of WPF and FPF on fasting insulin was secondary to a reduction in IR as indicated by the $25 \%$ in HOMA-IR, an estimate of IR. The data suggest that less insulin was needed to maintain fasting glucose concentrations. Other studies have observed similar effects in canned chickpeas $^{(17)}$ and cereal fibre ${ }^{(18)}$. Insulin resistance is considered a major risk factor for diabetes, CVD, hypertension, obesity and inflammation ${ }^{(19,20)}$. Moreover, whole yellow peas and fractionated yellow peas are high in insoluble fibre. A prospective cohort study demonstrated that diets rich in insoluble fibre reduced the risk of type 2 diabetes by $25 \%{ }^{(21)}$. Similarly, a meta-analysis by Schulze et al. ${ }^{(22)}$ revealed that cereal-derived fibre, a good source of insoluble fibre, was associated with a lower relative risk ratio for diabetes of 0.67 compared with soluble fibres from fruits and vegetables at 0.96 and 1.07 , respectively. SCFA production in the gastrointestinal tract secondary to microbial fermentation of fibres has been shown to increase insulin sensitivity $^{(23-26)}$. Researchers propose that SCFA reduce levels of circulating NEFA, a known inducer of $\mathrm{IR}^{(27)}$. The notion of whole and fractionated yellow peas evoking a prebiotic effect serves as a plausible mechanism to explain observed changes in insulin parameters. Why this effect occurred without acting on fasting glucose and/or postprandial glucose responses cannot, however, be reconciled using the present data.

The present study attempted to define the effect of pea treatments on body composition in the context of an energy-balanced paradigm. By preventing the changes in body weight, we demonstrated that WPF and FPF do not affect \%TFM, independent of the changes in body mass. The lack of effect on body composition was most likely due to controlling energy intake and maintaining body weight over the duration of each study phase. Furthermore, the results from the present study suggest that WPF or FPF do not contain bioactive compounds that up-regulate energy expenditure. Moreover, since subjects were required to consume all food provided by the study personnel during each study phase, a negligible effect on body composition with WPF and FPF treatments in the present study was observed in the absence of pulses triggering satiety-related suppression of food intake, a potential mechanism of action of yellow peas, and ultimately pulses, on body composition ${ }^{(17,28,29)}$.

Increased android adiposity is associated with CVD risk factors including IR, inflammation and atherosclerosis $^{(30,31)}$. In the present study, women demonstrated a shift in fat distribution from android to gynoid with WPF, suggesting that bioactives other than fibre are responsible for the effects observed. WPF contains the cotyledon which houses various proteins and phytochemicals including secoisolariciresinol, a lignan-type phyto-oestrogen at $13 \mu \mathrm{g} / 100 \mathrm{~g}^{(7)}$. Pea-derived secoisolariciresinol is converted to enterolactone by colonic microflora and subsequently absorbed. While oestrogen helps to regulate regional fat deposition by interacting with oestrogen receptor $\alpha$ $(\mathrm{ER} \alpha)$ and $\beta(\mathrm{ER} \beta)$ and up-regulating $\alpha_{2^{-}}$and $\beta$-adrenergic receptors, studies indicate that various phyto-oestrogens exhibit different affinities for ER $\alpha$ and ER $\beta$. For example, soya-derived phyto-oestrogens demonstrate ER $\beta$-binding specificity $^{(32)}$, while coumestrol has been shown to be an ER $\alpha$-specific agonist ${ }^{(33,34)}$. Although the biological effects of secoisolariciresinol are understudied, physiological levels of enterolactone were able to induce oestrogendependent reporter gene expression via ER $\alpha$ receptors ${ }^{(35)}$. Studies suggest that women express higher levels of subcutaneous $\mathrm{ER} \alpha^{(36)}$ and $\alpha_{2}$-adrenergic receptors ${ }^{(37)}$ compared with men. Since oestrogen favours subcutaneous fat deposition via $\mathrm{ER} \alpha$ - and $\alpha 2$-adrenergic receptors via lower lipolytic activity in subcutaneous adipose tissue ${ }^{(37,38)}$, we hypothesise that pea-derived secoisolariciresinol could be acting as an $\mathrm{ER} \alpha$ agonist in women through its conversion to enterolactone. Few studies have examined the effects of phyto-oestrogens on body composition. However, Sites et $a l{ }^{(39)}$ demonstrated that soya isoflavones reduced abdominal subcutaneous fat deposition in post-menopausal women and suggested that the preferential affinity of soya-derived phyto-oestrogens for ER $\beta$ may explain their results. The observation that urinary enterolactone levels tended to be higher in the WPF group compared with those in the WF group in the present study augurs for further exploration of the effects of enterolactone on body fat distribution.

Failure for WPF and FPF to reduce fasting glucose concentrations is most likely secondary to the fact that most individuals were already normoglycaemic with fasting glucose concentrations $<5.6 \mathrm{mmol} / \mathrm{l}$. Similar negative results have been observed with chickpea-fortified bread products $^{(40)}$ and high-fibre rye bread ${ }^{(41)}$. WPF and FPF also failed to change postprandial glucose responses when combined with an energetically balanced breakfast. Foods high in dietary fibre are thought to reduce postprandial glucose responses by interfering with glucose absorption $^{(42)}$. High levels of insoluble fibre found in yellow peas may have contributed to yellow peas inefficacy at reducing postprandial glycaemia since insoluble fibres are less effective than soluble fibres at blunting glycaemic responses $^{(43)}$. However, Guevin et al. ${ }^{(44)}$ noted that $10 \mathrm{~g}$ 
dietary fibre at 1:4 and 2:3 ratios of soluble to insoluble fibre failed to produce any effect on postprandial glycaemia, suggesting that factors other than fibre type are responsible for the varied results regarding the effect of pulses on glycaemic response. It should be emphasised that in the present study, in order to eliminate the confounding effects of fibre from the diet, some fibre was removed from the background diet, as breads were all composed of white flour. Hence, the energy density and amount of simple carbohydrates of the breakfast meal may have been in excess for some subjects, such that the dose of WPF or FPF did not reduce glucose absorption. On the other hand, the calculated glycaemic index of the breakfast meal excluding treatment was low at approximately 39.6 and was secondary to the high proportion of egg protein relative to carbohydrate content. Given that the glycaemic index of the breakfast meal was already reduced, postprandial glucose concentrations may have been blunted such that the quarter cup of peas during breakfast failed to exert any observable effect on glucose response. Finally, it has been suggested that traditionally cooked pulses, i.e. boiled, exert a greater effect on glucose response because of the lower surface area compared with equivalent amounts of pulse flour ${ }^{(45)}$. Smaller particles, as found in flours, would have allowed greater surface exposure to digestive enzymes and hence a higher rate of absorption $^{(46)}$. Hence, using flours as a vehicle for administering WPF and FPF in the present study may have prevented a blunting in postprandial glycaemic response.

The observation that within-group reductions in lipid concentrations for TC, LDL-C and HDL-C did not translate into changes between treatment groups suggests that alterations in fasting lipids were secondary to the NCEPStep 1 diet provided to volunteers during each treatment phase. The present results show no changes in lipid levels secondary to the WPF and FPF treatments. Previous studies suggest that the dose of pulses used in the present study was insufficient to induce a lipid-lowering effect. Fruhbeck et $a l^{(47)}$ noted significant reductions in TC, LDL-C and TAG with $90 \mathrm{~g} / \mathrm{d}$ raw and cooked bean flour, a dose that was almost double the $50 \mathrm{~g}$ WPF provided to the volunteers in the present study. Conversely, Calvert et $a l .{ }^{(48)}$ failed to observed a change in TC, LDL-C HDL-C and TAG when subjects received $50 \mathrm{~g} / \mathrm{d}$ defatted soyabean flour for $28 \mathrm{~d}$. The results from Calvert et al. ${ }^{(48)}$, together with the present findings, suggest that the dose administered may have been insufficient to elicit a significant change in circulating lipid concentrations.

\section{Conclusions}

In summary, the present results suggest that the fibre content of half a cup/d yellow peas (approximately $50 \mathrm{~g}$ ) in the form of WPF and FPF improves CVD and diabetes risk factors by reducing fasting insulin concentrations and markers of IR independent of food and energy intake.
The observation that women demonstrated a shift in subcutaneous fat deposition with WPF warrants further investigation into the phyto-oestrogenic effects of yellow peas.

\section{Acknowledgements}

We would like to thank Pulse Canada for funding the present study. The present study has no conflicts of interest. C. P. F. M. was responsible for conducting the research, analysing data and writing the manuscript. Moreover, C. P. F. M. provided input in designing the study. P. J. H. J. was instrumental in conceptualising and designing the research project. P. J. H. J. also contributed to writing the manuscript. We would also like to thank Kim Robinson, Xin Wang, Katherine Leung, Darren Speziale, Yen Ming Chan and kitchen staff for their assistance with the clinical trial, Gerber $^{\circledR}$ for their generous donation of the baby food used for flavouring the treatment muffins, Roche Diagnostics for providing glucose monitors and Best Cooking Pulses, Inc., for providing the whole and fractionated pea flours. Finally, we acknowledge Dr Edward Kesselman for his medical expertise.

\section{References}

1. Hu FB \& Willett WC (2002) Optimal diets for prevention of coronary heart disease. JAMA 288, 2569-2578.

2. Willett WC (2008) Overview and perspective in human nutrition. Asia Pac J Clin Nutr 17, Suppl. 1, 1-4.

3. Anderson JW \& Major AW (2002) Pulses and lipaemia, short- and long-term effect: potential in the prevention of cardiovascular disease. Br J Nutr 88, Suppl. 3, S263-S271.

4. Leterme P (2002) Recommendations by health organizations for pulse consumption. Br J Nutr 88, Suppl. 3, S239-S242.

5. Yang Y, Zhou L, Gu Y, et al. (2007) Dietary chickpeas reverse visceral adiposity, dyslipidaemia and insulin resistance in rats induced by a chronic high-fat diet. Br J Nutr $\mathbf{9 8}$, $720-726$.

6. Venn BJ \& Mann JI (2004) Cereal grains, legumes and diabetes. Eur J Clin Nutr 58, 1443-1461.

7. Mazur W (1998) Phytoestrogen content in foods. Baillieres Clin Endocrinol Metab 12, 729-742.

8. Valentin-Blasini L, Sadowski MA, Walden D, et al. (2005) Urinary phytoestrogen concentrations in the U.S. population (1999-2000). J Expo Anal Environ Epidemiol 15, 509-523.

9. Brault Dubuc M \& Caron-Lahaie L (1994) Nutritive Value of Foods, 2nd ed. St-Lambert, QC: Societe Brault-Lahaie.

10. USDA.gov. (2009) Inside the pyramid: how many vegetables are needed daily or weekly? http://www.mypyramid.gov/ pyramid/vegetables_amount_table.html (accessed 4 March 2009).

11. Mifflin MD, St Jeor ST, Hill LA, et al. (1990) A new predictive equation for resting energy expenditure in healthy individuals. Am J Clin Nutr 51, 241-247.

12. Volund A (1993) Conversion of insulin units to SI units. Am J Clin Nutr 58, 714-715.

13. Matthews DR, Hosker JP, Rudenski AS, et al. (1985) Homeostasis model assessment: insulin resistance and beta-cell function from fasting plasma glucose and insulin concentrations in man. Diabetologia 28, 412-419.

14. Brouns F, Bjorck I, Frayn KN, et al. (2005) Glycaemic index methodology. Nutr Res Rev 18, 145-171. 
15. Wolever TM \& Jenkins DJ (1986) The use of the glycemic index in predicting the blood glucose response to mixed meals. Am J Clin Nutr 43, 167-172.

16. Friedewald WT, Levy RI \& Fredrickson DS (1972) Estimation of the concentration of low-density lipoprotein cholesterol in plasma, without use of the preparative ultracentrifuge. Clin Chem 18, 499-502.

17. Pittaway JK, Robertson IK \& Ball MJ (2008) Chickpeas may influence fatty acid and fiber intake in an ad libitum diet, leading to small improvements in serum lipid profile and glycemic control. J Am Diet Assoc 108, 1009-1013.

18. Weickert MO, Mohlig M, Schofl C, et al. (2006) Cereal fiber improves whole-body insulin sensitivity in overweight and obese women. Diabetes Care 29, 775-780.

19. Ginsberg HN (2000) Insulin resistance and cardiovascular disease. J Clin Invest 106, 453-458.

20. Watson KE, Peters Harmel AL \& Matson G (2003) Atherosclerosis in type 2 diabetes mellitus: the role of insulin resistance. J Cardiovasc Pharmacol Ther 8, 253-260.

21. de Munter JS, Hu FB, Spiegelman D, et al. (2007) Whole grain, bran, and germ intake and risk of type 2 diabetes: a prospective cohort study and systematic review. PLoS Med 4, e261.

22. Schulze MB, Schulz M, Heidemann C, et al. (2007) Fiber and magnesium intake and incidence of type 2 diabetes: a prospective study and meta-analysis. Arch Intern Med 167, 956-965.

23. Thorburn A, Muir J \& Proietto J (1993) Carbohydrate fermentation decreases hepatic glucose output in healthy subjects. Metabolism 42, 780-785

24. Robertson MD, Currie JM, Morgan LM, et al. (2003) Prior short-term consumption of resistant starch enhances postprandial insulin sensitivity in healthy subjects. Diabetologia 46, 659-665.

25. Robertson MD, Bickerton AS, Dennis AL, et al. (2005) Insulin-sensitizing effects of dietary resistant starch and effects on skeletal muscle and adipose tissue metabolism. Am J Clin Nutr 82, 559-567.

26. Robertson MD (2007) Metabolic cross talk between the colon and the periphery: implications for insulin sensitivity. Proc Nutr Soc 66, 351-361.

27. Savage DB, Petersen KF \& Shulman GI (2007) Disordered lipid metabolism and the pathogenesis of insulin resistance. Physiol Rev 87, 507-520.

28. Delargy HJ, O'Sullivan KR, Fletcher RJ, et al. (1997) Effects of amount and type of dietary fibre (soluble and insoluble) on short-term control of appetite. Int J Food Sci Nutr $\mathbf{4 8}$, $67-77$.

29. Salas-Salvado J, Farres X, Luque X, et al. (2008) Effect of two doses of a mixture of soluble fibres on body weight and metabolic variables in overweight or obese patients: a randomised trial. Br J Nutr 99, 1380-1387.

30. Carey DG, Jenkins AB, Campbell LV, et al. (1996) Abdominal fat and insulin resistance in normal and overweight women: direct measurements reveal a strong relationship in subjects at both low and high risk of NIDDM. Diabetes 45, 633-638.

31. Tanko LB \& Christiansen C (2006) Adipose tissue, insulin resistance and low-grade inflammation: implications for atherogenesis and the cardiovascular harm of estrogen plus progestogen therapy. Climacteric 9, 169-180.

32. Morito K, Hirose T, Kinjo J, et al. (2001) Interaction of phytoestrogens with estrogen receptors alpha and beta. Biol Pharm Bull 24, 351-356.
33. Morito K, Aomori T, Hirose T, et al. (2002) Interaction of phytoestrogens with estrogen receptors alpha and beta (II) Biol Pharm Bull 25, 48-52.

34. Wu XT, Wang B \& Wei JN (2009) Coumestrol promotes proliferation and osteoblastic differentiation in rat bone marrow stromal cells. J Biomed Mater Res B Appl Biomater 90, 621-628.

35. Penttinen P, Jaehrling J, Damdimopoulos AE, et al. (2007) Diet-derived polyphenol metabolite enterolactone is a tissue-specific estrogen receptor activator. Endocrinology 148, 4875-4886.

36. Rodriguez-Cuenca S, Monjo M, Proenza AM, et al. (2005) Depot differences in steroid receptor expression in adipose tissue: possible role of the local steroid milieu. Am J Physiol Endocrinol Metab 288, E200-E207.

37. Richelsen B (1986) Increased alpha 2- but similar beta-adrenergic receptor activities in subcutaneous gluteal adipocytes from females compared with males. Eur J Clin Invest 16, 302-309.

38. Pedersen SB, Kristensen K, Hermann PA, et al. (2004) Estrogen controls lipolysis by up-regulating alpha2A-adrenergic receptors directly in human adipose tissue through the estrogen receptor alpha. Implications for the female fat distribution. J Clin Endocrinol Metab 89, 1869-1878.

39. Sites CK, Cooper BC, Toth MJ, et al. (2007) Effect of a daily supplement of soy protein on body composition and insulin secretion in postmenopausal women. Fertil Steril $\mathbf{8 8}$ 1609-1617.

40. Nestel P, Cehun M \& Chronopoulos A (2004) Effects of longterm consumption and single meals of chickpeas on plasma glucose, insulin, and triacylglycerol concentrations. Am J Clin Nutr 79, 390-395.

41. Juntunen KS, Laaksonen DE, Poutanen KS, et al. (2003) High-fiber rye bread and insulin secretion and sensitivity in healthy postmenopausal women. Am J Clin Nutr 77 , 385-391.

42. Jenkins DJ, Axelsen M, Kendall CW, et al. (2000) Dietary fibre, lente carbohydrates and the insulin-resistant diseases. Br J Nutr 83, Suppl. 1, S157-S163.

43. Jenkins DJ, Kendall CW, Axelsen M, et al. (2000) Viscous and nonviscous fibres, nonabsorbable and low glycaemic index carbohydrates, blood lipids and coronary heart disease. Curr Opin Lipidol 11, 49-56.

44. Guevin N, Jacques H, Nadeau A, et al. (1996) Postprandial glucose, insulin, and lipid responses to four meals containing unpurified dietary fiber in non-insulin-dependent diabetes mellitus (NIDDM), hypertriglyceridemic subjects. $J$ Am Coll Nutr 15, 389-396.

45. Araya H, Pak N, Vera G, et al. (2003) Digestion rate of legume carbohydrates and glycemic index of legume-based meals. Int J Food Sci Nutr 54, 119-126.

46. Araya H, Contreras P, Alvina M, et al. (2002) A comparison between an in vitro method to determine carbohydrate digestion rate and the glycemic response in young men. Eur J Clin Nutr 56, 735-739.

47. Fruhbeck G, Monreal I \& Santidrian S (1997) Hormonal implications of the hypocholesterolemic effect of intake of field beans (Vicia faba L.) by young men with hypercholesterolemia. Am J Clin Nutr 66, 1452-1460.

48. Calvert GD, Blight L, Illman RJ, et al. (1981) A trial of the effects of soya-bean flour and soya-bean saponins on plasma lipids, faecal bile acids and neutral sterols in hypercholesterolaemic men. Br J Nutr 45, 277-281. 